\title{
La imagen corporal en los medios de comunicación masiva
}

\author{
Claudia Iris Bazán ${ }^{1}$ y Rosinella Miño²
}

\begin{abstract}
Artículo
Material original autorizado para la publicación en la revista Psicodebate. Facultad de Ciencias Sociales. Universidad de Palermo.

Recibido 29-09-2014 | Aceptado 30-04-2015
\end{abstract}

\section{Resumen}

La preocupación por el peso que caracteriza a la mayoría de las mujeres actuales tuvo su origen en las investigaciones médicas que mostraron la relación entre la gordura y enfermedades como la hipertensión o las enfermedades cardiovasculares. Como muestra el cineasta y documentalista Michael Moore en su película "Sicko" del año 2007, las grandes compañías de salud estadounidenses recompensaban económicamente a quienes tenían un cuerpo más delgado y sancionaban a las personas con sobrepeso porque tenían mayores riesgos de contraer enfermedades y por lo tanto de generar pérdidas a las empresas de salud. A partir de ahí, el énfasis puesto en el control del peso y la realización de dietas hipocalóricas -y su asociación con la salud-alcanzó límites inesperados. En esta preocupación creciente por el peso, los Medios de Comunicación Masiva tuvieron y tienen un rol protagónico. El presente artículo analiza los efectos de la difusión mediática de dicho ideal estético/saludable, que contribuye a la construcción de una mujer sujeta a inagotables exigencias. Esas exigencias sociales tienen que ver con la perfección, el predominio de lo estético, el cuerpo saludable y la juventud eterna, las cuales garantizarían el éxito. Cuál es la relación que tienen la televisión, las revistas femeninas, Internet, la publicidad e incluso los juguetes infantiles con la expansión de "la cultura de lo light", del cuerpo ideal y la conducta saludable, son algunos de los interrogantes que se abordarán en el presente artículo, a partir de la exploración bibliográfica y de los Medios, de modo de contribuir a una mejor comprensión de este fenómeno. Finalmente, como posible solución al problema, se propone una estrategia de intervención del Estado sobre el modelo actual del

1 Universidad de Palermo, Universidad de Buenos Aires - Argentina; claudiaibazan@hotmail.com.

2 Universidad de la Cuenca del Plata - Argentina 
mercado, para la promoción del buen uso de la información y la prevención de Trastornos del Comportamiento Alimentario y otras enfermedades relacionadas a la mala alimentación.

Palabras Clave: delgadez, conducta dietante, salud, riesgo psicosocial, los medios.

\section{Abstract}

The concern about weight that characterizes most modern women stemmed from the medical research that showed the relationship between obesity and diseases such as hypertension or cardiovascular disease. As shown by the American filmmaker Michael Moore in his documentary film "Sicko" in 2007, large US health companies financially rewarded those with a thinner body and sanctioned overweight people because they had higher risks of disease and thus generate losses to their companies. From there, the emphasis on weight control and low-calorie dieting -and its association with health- reached unexpected limits. Mass Media had and have a leading role on this growing concern about weight. This article analyzes the effects of media on the aesthetic / healthy ideal, which contribute to the construction of a woman captured by endless demands. These social requirements are associated with perfection, the predominance of the aesthetic, healthy body and eternal youth, which would guarantee success. What relationship have television, women's magazines, Internet, advertising and even children's toys with the expansion of "the culture of light", the ideal body and healthy behavior are some of the questions that will be addressed in this Article. To contribute to a better understanding of this phenomenon, we will make a bibliographic and Media exploration. Finally, as a possible solution to the problem, a strategy of state intervention on the current market model for promoting good use of information and prevention of Eating Disorders and other diseases related to poor diet is proposed.

Keywords: thinness, dieting behavior, health, psychosocial risk, media. 
El ideal de salud y belleza ha ido cambiando con el tiempo. La preocupación por el peso que caracteriza a la mayoría de las mujeres actuales está relacionada con la difusión de un modelo estético corporal femenino delgado, que se aleja cada vez más del común denominador de las mujeres reales. Paralelamente, las personas quieren cuidar su salud y para eso tienen conductas que no siempre alcanzan el objetivo que se proponen.

Las conductas dietantes y el ideal de delgadez son un problema en la medida que ponen a las mujeres en situación de riesgo con respecto a su salud (Woodside \& Garfinkel, 1989), especialmente si se considera su asociación con los Trastornos del Comportamiento Alimentario (TCA) y la obesidad. Los TCA representan la tercera enfermedad crónica entre la población femenina adolescente y juvenil en las sociedades desarrolladas y occidentalizadas; no sólo por el número de casos nuevos aparecidos, sino también por la gravedad de la sintomatología asociada y la resistencia al tratamiento (Pelaez Fernández, Labrador Encinas \& Raich Escursell, 2006). La obesidad, por su parte, ya alcanzó límites epidémicos a nivel internacional, según la Organización Mundial de la Salud (2013). Esto pone de manifiesto la necesidad de analizar los factores psicosociales que favorecen la realización de dietas hipocalóricas en pos de un cuerpo cada vez más delgado; es decir los factores predisponentes; ya que las dietas podrían estar asociadas con el desarrollo de trastornos psico-fisiológicos. En este contexto, los Medios de Comunicación Masiva (de acá en adelante, los Medios), voceros y constructores de expectativas sociales, tienen sin duda un rol fundamental en la expansión de este modelo estético/saludable.

Los Medios promueven el ideal de delgadez a través de la difusión de patrones de belleza que ejercen un efecto extremadamente fuerte sobre las mujeres -población especialmente afectada por esta problemática. Algunos autores destacan el peso de la televisión en la difusión de valores y patrones relacionados con la estética de la delgadez y la "cultura de lo Light", que además son sinónimos de salud. Otros autores enfatizan el lugar que ocupan las revistas femeninas e internet -particularmente entre los jóvenes- en la construcción de los patrones de belleza. En la misma línea, los especialistas resaltan la incidencia de la publicidad explícita y encubierta, que vende cuerpos delgados para luego promocionar la venta de otros productos. En esta búsqueda progresiva de la delgadez, los juguetes infantiles también tienen influencia.

¿Puede sostenerse que los Medios aumenten la incidencia de los TCA y de la obesidad al difundir el ideal estético vigente? ¿Cómo limitar su influencia, dada la enorme inversión que los Medios realizan en dinero y esfuerzos, para influir y manipular a las personas? Como contracara, ¿cuál es el rol que los Medios podrían cumplir o efectivamente cumplen en la divulgación de información preventiva y salugénica, desde la educación informal? Estos son algunos de los interrogantes que se intentarán responder en este trabajo. 


\section{La delgadez y la comida dietética}

El modelo estético corporal femenino delgado se instaló por primera vez en las capas de la alta burguesía anglosajona, después de la Primera Guerra Mundial. Completó su difusión en todo el mundo occidental u occidentalizado a partir de la Segunda Guerra Mundial, y particularmente desde 1960, momento en que el énfasis puesto en el control del peso - dietas y delgadez- llegó a convertirse en una obsesión (Polivy \& Herman, 2002; Rutsztein, 1997; Toro, 2006). Múltiples factores favorecieron la instalación de este modelo de la delgadez: la evolución de la moda en el vestir; la progresiva exhibición pública del cuerpo; la proliferación de mujeres populares -como actrices o 'top models'- de cuerpos extremadamente delgados; la condena social de la obesidad e incluso del sobrepeso; la presión de la industria de 'lo light'; la expansión de gimnasios, centros de estética, nutrición y cirugía rectificadora; la extensión social del ejercicio físico y de la práctica deportiva; y sobre todo, los cambios en el ámbito social respecto del rol de la mujer. Finalmente, la globalización hizo posible que este modelo estético se extendiera por todo el mundo (Giddens, 1997; Polivy \& Herman, 2002; Toro, 2006).

La bibliografía sobre el tema indica que las mujeres occidentales púberes, adolescentes y jóvenes de clase social media alta son las más afectadas por este ideal. Sin embargo, según una investigación realizada con una muestra de 123 mujeres $^{3}$ argentinas de la Ciudad Autónoma de Buenos Aires (CABA) y del Conurbano Bonaerense (AMBA), pudo observarse que las mujeres evidencian una fuerte asociación entre delgadez, alimentos dietéticos y salud, sin importar la edad o la clase de pertenencia. Las mujeres de la muestra tenían conductas dietantes y valoraban la delgadez por razones estéticas y como forma de proteger su salud. La preocupación excesiva por la dieta que evidenciaron los resultados de la investigación sólo se tradujo en aumentar la ingesta de comida dietética, lo que no permite optimizar la relación entre los alimentos y la salud, y acceder así a una mejor calidad de vida (Bazán, 2011; Bazán \& Ferrari, 2010, 2011). La obsesión por las dietas priva a las personas de su capacidad para regularse naturalmente. En muchos casos genera exactamente lo contrario de lo que busca: sobrealimentación, sobrepeso y obsesión por la comida (Fraser, 1998).

\section{Del cuerpo real al cuerpo mediático}

\section{La televisión}

Los Medios promueven el ideal de delgadez difundiendo patrones de belleza que

3 Se seleccionaron solo mujeres por considerarse la población de mayor riesgo. 
impactan especialmente en las mujeres. Bordo analiza los mitos, ideologías y patologías que influyen en la construcción del cuerpo femenino. Señala que si bien es un saber compartido que las estrellas y modelos son producto de numerosas intervenciones en el rostro y cuerpo (desde cirugía hasta maquillaje o 'photoshop'), la mujer común pasa por alto estos datos y construye una imagen ideal de belleza imposible de alcanzar. Así, el modelo estético ideal de nuestra época se corresponde con una imagen fabulada, distinta del cuerpo real de carne y hueso (Mancilla Díaz et al., 2006).

No es sorprendente que los Medios sean acusados de aumentar la incidencia de los TCA, ya que las imágenes mediáticas de físicos idealmente delgados motivan a las personas a intentar alcanzar la delgadez. En el mismo sentido, también se los acusa de distorsionar la realidad, ya que las modelos y celebridades que aparecen en ellos son producto de tratamientos especiales para alcanzar y mantener la delgadez, o son naturalmente delgadas -lo cual no es representativo de la norma (Polivy \& Herman, 2002).

Según Behar (2010), la televisión pareciera ser el medio de comunicación de mayor impacto en la difusión de valores y patrones relacionados con la estética de la delgadez. Por su parte Toro (2006) sostiene que, aunque la televisión no tiene una influencia tan determinante como la de las revistas, también ejerce presión, al ser más significativo el tipo de programas que el sujeto mira que la cantidad de horas que pasa frente al televisor. Los programas deportivos, por ejemplo, pueden ser inocuos, pero no los programas donde aparecen mujeres delgadas (como las películas o los videos musicales).

Por su parte, Silverstein, Peterson y Perdue (1996, como se citó en Toro, 2006), analizaron el aspecto físico de los hombres y mujeres que aparecían en los cuarenta programas televisivos de mayor audiencia de EEUU - programas vistos en todo el mundo. El $60,1 \%$ de las mujeres analizadas eran delgadas, mientras solo el $17,5 \%$ de los varones lo eran. Además, se juzgó que el $25 \%$ de los varones tenían sobrepeso, contra sólo el 5\% de las mujeres. En concordancia con la bibliografía sobre el tema, estos datos muestran que el peso tiene mayor significación social entre las mujeres que entre los varones.

Sin embargo, estas afirmaciones deben matizarse. Si bien las adolescentes expuestas a muchas horas de programas televisivos en los que aparecen cuerpos idealmente delgados pueden como consecuencia propender a la insatisfacción corporal, esto no significa que pueda establecerse una relación causal. Otro escenario posible es que las jóvenes con insatisfacción corporal estén particularmente interesadas en este tipo de programas (Polivy \& Herman, 2002).

\section{La prensa escrita}

Las revistas marcan tendencias. Crispo, Figueroa y Guelar (1998) lo 
ejemplifican a través de una noticia presentada en una revista, cuyo título era: “No está harta de ser usted misma? Sea definitivamente otra”. Acompañaban la nota dietas adelgazantes y estrategias quirúrgicas para modificar todo el cuerpo. La vigencia de las observaciones de los autores puede verse en una publicidad de técnicas de lipoescultura, que un cirujano plástico mexicano promociona por Internet. El texto usado es el siguiente:

iiiTrae el cuerpo que tienes y llevate el que quieres!!! Ahora todo es posible con una Lipoescultura... existen diferentes técnicas. Para volúmenes pequeños se utiliza la técnica convencional, para volúmenes grandes se puede recurrir a la liposucción asistida con láser o ultrasonido (Núñez Virgen, 2012).

Toro (2006) sostiene que se ha demostrado sin lugar a dudas que la exposición a revistas donde aparecen figuras femeninas de cuerpo 'ideal' potencia la interiorización del ideal corporal delgado al tiempo que aumenta la insatisfacción corporal. El especialista señala que, según un estudio realizado por Field y colaboradores (1999, como se citó en Toro, 2006) con 600 preadolescentes y adolescentes, casi el $70 \%$ de las entrevistadas reconocieron que las fotografías de modelos habían influido en su concepción de cómo debe ser el cuerpo femenino, y el $47 \%$ dijo que al ver esas fotografías quería perder peso. De hecho, hallaron una correlación significativa entre la lectura de revistas de moda y la práctica de dietas para perder peso, así como la inclusión en programas de ejercicio físico.

En la investigación desarrollada por Jiménez-Cruz y Silva-Gutiérrez (2010), las participantes que fueron expuestas a imágenes de mujeres delgadas reportaron emociones más negativas hacia sus cuerpos que aquellas que observaron imágenes de mujeres con sobrepeso. Este tipo de investigaciones sugieren que el ideal transmitido a través de los Medios promueve sensaciones de malestar que pueden afectar la conducta alimentaria. Por eso los datos reportados por David Garner adquieren relevancia. Según el autor, entre 1986 y 1996 la cantidad de artículos sobre dietas hipocalóricas que aparecieron en las revistas de tirada masiva aumentó en un 70\% (Crispo et. al., 1998). En consonancia con estos datos, los editores de revistas de tirada nacional sostienen que incluir la palabra 'dieta' en la tapa aumenta significativamente el número de ventas (N. Bär, comunicación personal, 15 de junio, 2012).

El mundo de la moda también da cuenta de las exigencias que presionan a las mujeres para alcanzar una imagen femenina ideal cada vez más delgada. Según Casas, Raich y Mora (2000), de un grupo de 17 'top models', el 16,7\% presentaron bajo peso, y el 83\% restante tenían un Índice de Masa Corporal (IMC) compatible con la anorexia. Según Snow y Harris (1986), de 1950 a 1985 las mujeres con 
sobrepeso prácticamente desaparecieron de las revistas femeninas. Garner y colaboradores (1980, como se citó en Toro, 2006), destacan que desde 1960 a 1979 las modelos de las páginas centrales de Playboy y las concursantes de Miss America se fueron haciendo cada vez más delgadas. En contraposición, Leit, Pope y Gray (2001, como se citó en Toro, 2006) señalan que los modelos masculinos de la revista Playgirl, de 1973 a 1997, se fueron haciendo más musculosos.

Los Medios, además, suelen transmitir mensajes contradictorios en lo que hace a la salud y a la alimentación, que pueden acarrear consecuencias negativas en la población. En el mes de febrero de 2006, por ejemplo, salieron dos notas consecutivas en el diario Clarín. En la primera, Elustondo (2006), un especialista de la Universidad de Washington, Saint Louis, sostenía que una dieta variada, y equilibrada, pero pobre en calorías, retrasa el envejecimiento. Según la página de Internet de dicha Universidad ${ }^{4}$ el especialista en medicina y metabolismo Luigi Fontana, del Centro de Nutrición Humana de la Escuela de Medicina, se interesó en nutrición, envejecimiento y longevidad; centrándose en el papel que pueden jugar la restricción severa de calorías, las dietas a base de vegetales y el ejercicio de resistencia, para retardar el proceso de envejecimiento. En la segunda, Orlando (2006) en respuesta a la anterior, cardiólogo y miembro de la Sociedad Argentina de Obesidad y Trastornos Alimentarios (SAOTA), afirmaba que las dietas hipocalóricas sostenidas a largo plazo no aportan la suficiente cantidad de minerales, entre otros elementos esenciales que el cuerpo necesita. En la nota se destacaba que se debe hacer un seguimiento muy estricto del paciente dietante y evaluar los riesgos, ya que estas dietas pueden producir hipoglucemia o desencadenar problemas cardíacos.

\section{La publicidad y la salud}

La publicidad también es central en la promoción tanto del ideal de belleza vigente como del ideal de salud, y se despliega a través de distintos medios. Creadora de necesidades, incita al consumo al hostigar a los ciudadanos permanente y sistemáticamente con mensajes explícitos e implícitos. Vende cuerpos delgados para luego promocionar la venta de otros productos: alimentos dietéticos, medicamentos que ayudan a adelgazar, técnicas de modelado del cuerpo (como cirugías y lipoaspiración), centros de actividad física, etcétera. La mayoría de los estudios destaca el lugar de privilegio que los Medios dan a la estética corporal, a veces relacionándola con la necesidad de adelgazar y otras no.

Se ha observado que las publicidades, especialmente aquellas que invitan directa o indirectamente a adelgazar, afectan a las mujeres en su deseo de hacer

4 http://chn.dom.wustl.edu/faculty/luigi-fontana-md-phd.html 
dietas, con particular impacto en las mujeres jóvenes y adolescentes que padecen trastornos de la alimentación (Nunes, 2006; Toro, 2006). Sin hacer un análisis detallado -aunque se considera de interés para futuras investigaciones-, sino producto de la simple observación de los Medios locales, puede observarse en la publicidad una creciente asociación entre los alimentos 'cero calorías' y la salud.

Carrillo Durán (2005) afirma que en términos generales solo se destaca la mala influencia de los Medios -en el ámbito general y en particular con relación a la población que padece TCA- y consecuentemente las opiniones en su defensa son mucho más esquivas. Difícilmente se subraye el esfuerzo que realizan algunos Medios por revertir estas tendencias.

Si bien no puede desconocerse que se sobredimensiona la responsabilidad de los Medios, sus esfuerzos por revertir la tendencia dietante son aislados. En general, los Medios responden a intereses económicos y no están suficientemente controlados, por lo que es difícil evaluar sus efectos. Como enfatiza Strasburger (2010) con relación a las adicciones respecto del abuso que los adolescentes hacen del alcohol, el tabaco y los medicamentos, el papel que juegan los Medios puede ser clave. El autor destaca que se gastan más de 25 billones de dólares al año en publicidad y que ésta ha demostrado ser efectiva.

Por eso, la American Academy of Pediatrics (Academia de Pediatría de Estados Unidos) recomienda la prohibición de publicitar tabaco en los Medios, y la necesidad de limitar la publicidad de alcohol, evitar la exposición de los niños pequeños a cualquier contenido relacionado con drogas en la televisión, Internet y en las películas de clasificación 'apta para menores'. Asimismo, propone incorporar el tema de la publicidad y los Medios en los programas de prevención del abuso de sustancias y la implementación en el aula de programas de educación acerca de los Medios (Strasburger, 2010).

Así como la publicidad influye en el consumo de sustancias adictivas, también lo hace en la transmisión y construcción de la imagen corporal ideal, del cuerpo perfecto. Anderson y Pempek (2005, como se citó en Larraín Sundt, Camus, Orellana \& Arrieta, 2009) estiman que el estadounidense promedio es hostigado con más de mil avisos diarios, la mayoría de los cuales promueven y relacionan la sexualidad con la belleza y la extrema delgadez en las mujeres. En ese sentido, Larraín Sundt, Camus, Orellana y Arrieta (2009) sostienen que la sociedad actual enfatiza que el papel más importante de la mujer es ser atractiva físicamente. Los Medios perpetúan y refuerzan esta idea sugiriendo que la mujer vale fundamentalmente, por su imagen corporal.

Las relaciones con las personas del otro sexo están atravesadas por el deseo de agradar y para la mujer ser bella es estar delgada, aunque esto no siempre sea lo que el hombre busca. La publicidad, entonces, usa estereotipos y los transmite 
en un espacio concentrado. Es un reflejo de lo que la sociedad demanda, valora y prefiere; sino, carecería de sentido; ningún empresario pagaría por un anuncio que no identifique a su producto con su público (Carrillo Durán, 2005).

Pero la publicidad no sólo es un reflejo de la sociedad, además crea tendencias. Un ejemplo de esto fue la campaña que realizó una conocida marca de cerveza que buscaba conquistar al público adolescente, la cual tuvo un rol protagónico en la disminución de la edad en la que los jóvenes comienzan a consumir alcohol (González \& Wallace, 1990).

En consonancia con lo expuesto, Skatrud-Mickelson, Adachi-Mejia, MacKenzie y Sutherland (2012) denuncian la falta de investigación en torno a los efectos de la publicidad encubierta relacionada con comidas y bebidas que aparece en las películas, especialmente aquellas que están dirigidas a los más jóvenes. En sus investigaciones encontraron que las películas promueven un tipo de consumo que es inconsistente con las recomendaciones dietarias. Destacan que dada la crisis actual de la Salud Pública con respecto al aumento de los casos de obesidad, futuras investigaciones deberían estudiar los efectos que produce la exposición permanente a hábitos dañinos para la salud.

Sin embargo, como señala Carrillo Durán (2005), no es lo mismo la publicidad que invade los Medios que la información que recibimos de ellos; los caminos de influencia que utilizan ambas formas de comunicación son diferentes. Si bien esto es así, no se puede desconocer, por ejemplo, que gran cantidad de supuestas notas periodísticas de divulgación que aparecen en diarios y revistas, en realidad son publicidad encubierta.

En este mismo sentido, en el ámbito local, es profusa la publicidad que recomienda alimentos dietéticos por sus supuestas propiedades saludables, la cual es presentada por 'especialistas en salud' (incluso se incluye el número de matrícula del profesional) u otros referentes sociales. Por ejemplo, hay una publicidad televisiva de yogurt que promociona alimentos dietéticos, afirmando que su consumo es garantía de vitalidad y salud: "Animate a llenar tu vida de vitalidad [...] animate a lo que te hace bien". 5

No hay un control claro respecto de la veracidad de las afirmaciones que aparecen en este tipo de publicidades y falta investigación que analice las consecuencias que pueden tener sobre la población.

\section{Internet}

Internet también tiene un papel significativo en la construcción del ideal femenino. En los países desarrollados especialmente, se ha convertido en el medio por excelencia de comunicación y de acceso a la información de muchos jóvenes

5 Esta publicidad puede verse en https://www.youtube.com/watch?v=bLcz3QSkWC0 
y adolescentes. Según los Índices de Desarrollo del Banco Mundial (The World Bank, 2014), mientras en el año 2000 de cada 100 personas 6.8 eran usuarios de Internet, en 2012 había alcanzado los 35 usuarios. Su crecimiento es exponencial.

El uso de Internet no es positivo o negativo en sí mismo, sino que su impacto sobre la subjetividad depende fundamentalmente de las motivaciones e intenciones que dirigen su utilización. Si bien no es fácil determinar los bordes que separan un acceso normal o patológico a Internet, sus consecuencias podrían dirimirse en términos de exclusión o inclusión de experiencias alternativas (Bazán $\&$ Bóveda, 2005). Pero más allá del uso que se haga de Internet, a través de ella circulan imágenes, información, publicidad que responden a los mismos patrones mencionados en los apartados anteriores.

Un uso claramente patológico de Internet es el que caracteriza a los usuarios de sitios como la Red "pro-aNa" - pro anorexia- que fomentan el desarrollo de la anorexia y otras patologías afines. Un estudio realizado por Chesley y colaboradores (2003, como se citó en Toro, 2006) pudo detectar unos 500 sitios "pro-aNa". En ellos se dan instrucciones para iniciar y mantener la anorexia, se recomiendan ejercicios, medicamentos, dietas, se muestran imágenes que motivan a desarrollar la anorexia y se promocionan 'grupos de autoayuda' donde se compite por alcanzar el peso 'ideal', cada vez más bajo. El estudio de referencia concluye que este tipo de páginas están más organizadas, son más exhaustivas y más numerosas que aquellas destinadas a la promoción de la salud y la recuperación de la enfermedad (Toro, 2006).

Como ejemplo de este tipo de sitios, se transcriben algunos Mandamientos $a N a$ y sugerencias para Ocultar a $a N a$, de una página de Internet tomada al azar. ${ }^{6}$ Mandamientos aNa: "Si no estás delgada no eres atractiva", "Estar delgada es lo más importante, toma laxantes, muérete de hambre, lo que sea para parecer más delgada", "No comerás sin sentirte culpable", "Estar delgada y no comer demuestran la auténtica fuerza de voluntad y el nivel de éxito". Ocultar a aNa: "Sonreír todo el tiempo, nunca demostrar nada diferente al placer de verse bien", "iiiNo decirle NUNCA JAMÁS a nadie!!! Es mejor hacerse el loco por el peso que estás bajando, pero recuerda que JAMÁS LE DEBES DECIR A NADIE, Y MUCHO MENOS DECIR A QUIÉNES CONOCES CON ESTE MODO DE VIDA", "Si las van a obligar a comer y ustedes no quieren, decir "oh, pobres animales'. También pueden decir que vieron morir atropellado a un perrito (y si manejan, decir que fueron ustedes, créanme, ipor dos semanas nadie las obligara a comer!) y aún mejor si lo dicen con lágrimas en los ojos--

6 http://dayanna-mahm.blogspot.com.ar/2007/08/oracion-para-mia-y-ana-estricta-es-mi.html 


\section{Los juguetes infantiles}

Los juguetes infantiles merecen un tratamiento especial. En este sentido, la muñeca Barbie es paradigmática. Nació en 1959, cuando comenzó oficialmente su producción masiva. Ruth y Elliot Handler, sus creadores, tenían una hija llamada Barbara -Barbie- que dio nombre a la nueva muñeca. El juguete no representaba un bebé y con él las niñas podrían ser 'algo más que mamás'. Su hijo Kenneth (Ken), por su parte, dio nombre a la pareja de Barbie. Brownell y Napolitano (1995, como se citó en Toro, 2006) calcularon los cambios que debían producirse en el hombre y la mujer promedio, si tuvieran que responder a las medidas de Barbie y Ken, respectivamente. Para ser como Barbie, la mujer promedio debería crecer 60 centímetros, aumentar 13 centímetros de contorno de busto, estirar su cuello 8 centímetros y disminuir 15 centímetros de cintura. Asimismo, para asemejarse a Ken, el varón promedio debería crecer 50 centímetros de altura, 28 de tórax y 20 de circunferencia de cuello. Ambos muñecos responden a los estereotipos femenino y masculino de fines del siglo XX (Toro, 2006). Las niñas desde muy temprana edad (dos años en adelante) juegan con estos muñecos, que pueden transformarse fácilmente en modelos de identificación para millones de criaturas.

\section{El contexto socio-cultural}

Sin duda en la actualidad los cambios producidos en la imagen corporal se deben, en parte al menos, al extraordinario poder de difusión de cualquier mensaje mediático. Nunca como en este momento histórico los mismos mensajes habían llegado a tantas personas. Debe reconocerse la presión que ejercen los Medios en la difusión del modelo estético corporal delgado, que es un factor de riesgo fundamental para los TCA. En todo el mundo se ven las mismas películas, anuncios y cuerpos; idénticos criterios estéticos llegan a los ciudadanos de cualquier país (aunque esto no sea lo único que ofrecen los Medios). La difusión del modelo corporal delgado va unida de modo inevitable a la promoción de insatisfacción corporal y, por lo tanto, al riesgo de desarrollar TCA (Toro, 2006).

Por lo tanto, la información que brindan los Medios no es inofensiva. Como destaca Bender (1993), hoy los periodistas son casi profetas. Todo lo que se publica es considerado cierto o al menos 'algo habrá de cierto'. "Los oráculos modernos son los personajes públicos, las estrellas de cine, TV o deportistas, cuyas recomendaciones respecto de un alimento, régimen dietético o libro, llegan a impresionar a millones de personas" (Bender, 1993, p. 363).

A pesar de la influencia que tienen los Medios sobre la población, cada persona reacciona de modo diferente ante los mismos estímulos; las características individuales modelan su impacto. Sin embargo, es necesario aclarar que las mujeres -sobre quienes el peso del ideal corporal tiene más importancia- a su 
vez están insertas en un entramado social, compuesto fundamentalmente por su familia y grupo de pares, que a su vez reproducen los ideales vigentes, lo que multiplica los efectos de los Medios. Además, las mujeres -en particular las madres- son las encargadas de la mesa familiar y por lo tanto de transmitir las pautas alimenticias a las nuevas generaciones (Martín Criado, 2007; Martín Criado \& Moreno Pestaña, 2005).

Las adolescentes aprenden de sus pares ciertas actitudes, como la importancia de la delgadez, y conductas, como hacer dietas o purgarse (Levine et al. 1994, como se citó en Polivy \& Herman, 2002). De modo homogéneo, ellas tienden a preocuparse por su imagen corporal. Esto sugiere tanto la influencia directa de los pares, como que las jóvenes con similares preocupaciones tienden a juntarse (Ennett \& Bauman, 1994, como se citó en Polivy \& Herman, 2002). Es difícil evaluar la influencia relativa de los pares, los Medios y la familia, cuando todos se orientan en la misma dirección (Polivy \& Herman, 2002).

La preocupación y los comentarios que los padres hacen respecto del cuerpo de sus hijos, la conducta dietante de los padres -especialmente de las madres-, las conversaciones entre pares, la comparación de los cuerpos y las críticas a veces despiadadas de los amigos, también contribuyen al surgimiento de TCA o al menos de insatisfacción corporal, y sin duda a la construcción del cuerpo ideal. Los beneficios secundarios que los trastornos de la alimentación pueden ofrecer a las mujeres, retroalimentan la problemática. Por ejemplo, los halagos y felicitaciones por parte de familiares, novios y amigos por la pérdida de peso puede aumentar la autoestima, mientras incrementa el deseo de estar más delgada (Mancilla Díaz et al., 2006; Polivy \& Herman, 2002; Vivas \& Luigli, 2006). Por el contrario, la preocupación de los familiares y amigos puede ser un refuerzo social valioso.

Las exigencias profesionales también influyen en el deseo de estar delgados y pueden menoscabar la autoestima. En algunos trabajos, la presión ejercida sobre el aspecto corporal para acceder al mundo profesional se manifiesta abiertamente ya desde el anuncio, exigiendo "buena presencia". En otros es un requerimiento implícito del entrevistador. En el mundo contemporáneo se homologa a la mujer delgada con la exitosa; por el contrario, la obesidad es considerada un símbolo de dejadez y esto se trasladada al ámbito laboral, aunque la correlación no sea real (Carrillo Durán, 2005).

Paralelamente, hay una preocupación creciente de la población en general por tener 'una vida sana'. En una página de Internet (Fundación Vivo Sano, 2005) que apunta justamente a este objetivo, se presenta una guía para comer sano cuya primera regla es "debes escoger alimentos que sean bajos en grasas saturadas y en colesterol. También debes limitar tu ingesta de azúcar y sal. Debes comer más alimentos con fibra, como frutas, vegetales y cereales". En otra página de Internet (López, s.f.) 
encabeza la sección 'Vida Sana' de uno de los diarios nacionales de mayor tirada, la siguiente nota dirigida a las mujeres (cuya fuente es especialistas en nutrición):

¡Adiós rollitos! Guerra a las grasas: ¿se puede adelgazar en forma localizada? Hablar de grasa corporal no es lo mismo que hablar de sobrepeso. Es más, podemos ser flacas ${ }^{7} \mathrm{y}$, sin embargo, tener esos molestos "rollitos" en algunas zonas. Para buscar una solución, charlamos con varios especialistas.

Sin duda, entre el contexto social en el que las personas desarrollan su vida cotidiana y los Medios hay una dialéctica permanente de mutua construcción.

\section{Discusión}

Información como la que se menciona en los apartados anteriores se impone permanentemente a la población a través de los Medios. Limitar su influencia se hace cada vez más difícil, ya que es mucho mayor la inversión de dinero y esfuerzos para lograr nuevos y más efectivos medios para influir y manipular a las personas con el fin de incrementar el consumo, que lo que se invierte en investigación para entender estos fenómenos y tratar de reducir su influencia. Más lento y más difícil aún es que estas limitaciones alcancen a ser legisladas. Además, como denuncian Skatrud-Mickelson et al. (2012), si se legisla acerca de los límites que se deben imponer a las publicidades, por ejemplo, surge publicidad encubierta en las películas. En la mayoría de los casos, el mercado termina imponiéndose.

Los Medios contribuyen fuertemente a la construcción de los valores y expectativas sociales, tanto de modo positivo como negativo. Sin embargo, su influencia no es tan directa. Su ascendiente dependerá de aspectos personales (físicos y psicológicos), así como del entorno familiar y laboral, por mencionar algunos de los más significativos. Por eso, los esfuerzos deben tanto dirigirse al análisis de los Medios y sus consecuencias en la subjetividad y en la sociedad como conjunto, como apuntar a la prevención a través de programas de educación que contribuyan a conformar sujetos críticos, capaces de analizar, cuestionar y tamizar la información que reciben de los Medios.

Para ello el papel de los Estados es fundamental. Frente a un mercado que se impuso como el ente regulador del consumo de la sociedad con diversos efectos nocivos, los Estados deben intervenir y tomar un papel protagónico, como responsables de regular el cuidado de la salud bio-psico-social de las personas, con estrategias que estén a la altura de los modos propios de la sociedad actual. En

7 El destacado es nuestro. 
este sentido, los programas de prevención pueden ser pensados como una estrategia indirecta, es decir no como rivales del mercado sino como aliados estratégicos. El objetivo no sería censurar a los Medios por transmitir ideales que atentan contra la salud de las personas, sino regular los modos y la información que es transmitida, sobre la base de todos los estudios que demuestran la nocividad de estos impactos.

Reconociendo esto y sin dejar de lado la predisposición de los sujetos con ciertas características físicas y/o psicológicas para ser mayormente receptivos a esos efectos nocivos, se podría pensar la estrategia del Estado en una serie de etapas:

Etapa de la base teórica: reglamentación en los sistemas judiciales

Etapa de la instalación en los sistemas institucionales: educación y salud

Etapa de regulación de los Medios.

La Reglamentación implica un reconocimiento de la problemática de parte de los Estados, a la vez que su compromiso. El papel de la OMS es imprescindible para aportar a la fundamentación teórica, así como de investigaciones científicas que demuestren la existencia de la asimilación de los alimentos dietéticos como alimentos saludables, en la búsqueda del cuerpo ideal y su relación con los Medios.

En cuanto a su Instalación en las instituciones tendrían lugar los programas de prevención en sí mismos. Su modalidad implicaría una Intervención Inespecífica (Carballeda, 2008) operando de manera indirecta y colectiva, sobre los posibles factores del consumo masivo y desmedido, al establecer planes de educación con contenidos de información acerca de los valores nutricionales necesarios para la salud integral del ser humano. Talleres donde el grupo familiar, no sólo el niño/ estudiante, tenga que comprometerse en llevar a cabo una actividad con base en el cuidado de la salud general, en tanto que reconocemos una sociedad impactada por los valores regulados por el mercado desde hace varias décadas; por lo que los padres recibirían también en este caso una intervención directa. Esto contribuiría a fomentar una alimentación saludable que pueda contribuir a que los niños cuestionen el cuerpo idealizado impuesto por los Medios, en contraste con el cuerpo saludable.

Es esperable que los niños -también adolescentes y adultos- de esta década "no quieran comer vegetales", "no les gusta tomar leche"; "no les gusta el pescado", cuando los padres no sólo acompañan sino también aprueban estas posturas, sin cuestionarse sus efectos sobre la salud a largo plazo. Situación que arrastra la inquietud acerca de los esquemas de alimentación de las personas de esas generaciones. ¿Podrá estar asociado con la estructura familiar actual? Padres que casi no están con sus hijos porque ambos deben salir a trabajar, hijos que pasan más tiempo en instituciones, hijos que no obedecen a los padres, etcétera.

Desde la institución de la salud se deberían establecer los programas de prevención directos. La característica de la Salud Pública actual es la instalación de la Interdisciplina, donde se reconoce que el trabajo en equipo tiene mayores 
alcances y logros que la labor unilateral (Stolkiner, 2005). En este punto, existen en la Argentina equipos Interdisciplinarios de Salud Mental ${ }^{8}$ bajo la modalidad del "Programa Nacional de Salud Mental y Adicciones" (Ministerio de Salud, s. f.). Apunta sin duda a la intervención preventiva sobre las adicciones a sustancias psicoactivas, pero no se reduce a eso, ya que Salud Mental es un concepto tan amplio como manifestaciones psicosociales existan y la imagen corporal idealizada podría entonces ser considerada como tema específico de la Salud Mental.

Sería entonces fundamental instalar la noción de imagen corporal saludable como un tema concreto de Salud Mental en Salud Pública, siendo al menos uno de sus objetivos la prevención de los efectos negativos de la correlación ilusoria delgadez/salud (Bazán \& Ferrari, 2011). Esto es, evitar el mayor número de casos posibles de TAC y todas las patologías asociadas a la mala alimentación.

La Regulación de la Información de los Medios apunta sobre todo a las publicidades, con el foco puesto en dar información real y necesaria sobre el producto, manejando un concepto científicamente fundamentado de "saludable".

Estas estrategias podrían tener como resultado que las personas aprendan a alimentarse saludablemente y que al momento de querer bajar de peso reconozcan que los alimentos hipocalóricos tienen ciertas desventajas nutricionales. Consumirlos sería una elección personal, sin quedar atrapados en la ilusión de que comer comida de dieta hipocalórica es necesariamente sinónimo de comer sano.

El Estado no está completamente desentendido del tema. Por ejemplo, existen programas de prevención en Educación, bajo el nombre de Kiosco Saludable, cuyo objetivo es cambiar las golosinas por frutas y alimentos elaborados nutricionalmente para regular el consumo de los niños en las escuelas. Estos programas se encuentran funcionando en cada provincia según su propia reglamentación -como por ejemplo la Ley No 6914 (2012) de la Provincia del Chaco. Pero estas acciones no pueden ser aisladas y discontinuas, sino que deberían ser parte de un plan integral que fomente tanto la intervención sobre la población, como la investigación sistemática acerca de la conducta alimentaria, la imagen corporal, los efectos de los Medios y la presencia del Estado.

8 Estos equipos operan bajo la modalidad de talleres de prevención de diferentes temas específicos: Suicidios, Embarazos Adolescentes no Deseados y ETS, Violencia Familiar, entre otros, así como también Talleres de Capacitación Específica: la Huerta Orgánica Comunitaria y en la Casa, Costura y Confección de Indumentarias (Cooperativas), etc. 


\section{Referencias}

Bazán, C. I. (2011). La delgadez y las dietas ¿son más sanas? Detección en mujeres argentinas de la correlación ilusoria "a mayor delgadez, mayor salud”. España: Editorial Académica Española EAE.

Bazán, C. I. \& Bóveda, F. (2005). La comunicación vía Internet. Dioses o demonios. Revista de la Universidad de Ciencias Empresariales y Sociales: Subjetividad y Procesos Cognitivos, 7, 72-89.

Bazán, C. I. \& Ferrari, L. (2010). El ser y el deber ser de las conductas alimentarias en un grupo de mujeres la Ciudad Autónoma de Buenos Aires y del Conurbano Bonaerense. Revista del Instituto de Investigaciones de la Facultad de Psicología. 15(1), 25-46.

Bazán, C. I. \& Ferrari, L. (2011). Las dietas hipocalóricas y la delgadez como sinónimos de salud en un grupo de mujeres de la Ciudad Autónoma de Buenos Aires y el conurbano Bonaerense. Cuadernos Sociales, 11, 37-73.

Behar, R. (2010). La construcción cultural del cuerpo: El paradigma de los trastornos de la conducta alimentaria. Revista chilena de neuro-psiquiatría, 48(4), 319-334.

Bender, A. E. (1993). Dietas "mágicas” y otros errores. En F. Grande Covián, G. Varela, \& D. Conning (Eds.), Reflexiones sobre nutrición humana. Bilbao: Fundación BBV.

Carballeda, A. (2008). La prevención inespecífica en el campo de la drogadicción. Buenos Aires: Margen.

Carrillo Durán, M. V. (2005). Factores socioculturales en los TCA. No sólo moda, Medios y publicidad. Trastornos de la conducta alimentaria, 2, 120-141.

Casas, H., Raich, R.M. \& Mora, M. (2000). Modelos, medidas, publicidad. Trastornos Alimentarios. Cuadernos de Medicina Psicosomática y Psiquiatría de Enlace, 54, 55-59.

Crispo, R., Figueroa, E. \& Guelar, D. (1998). Anorexia y Bulimia. Lo que hay que saber. Barcelona: Gedisa.

Elustondo, G. (2006, 8 de febrero). Las dietas hipocalóricas. Demuestran que comer poco y sano retrasa el envejecimiento. Clarín. Recuperado de http:// 
www.therafarma.com.ar/paginas/ig/comerpoco.pdf

Fraser, L. (1998). La trampa de la Dieta. Revista Perspectivas Sistémicas, 10(49), $5-7$.

Fundación Vivo Sano (2005). Guía para comer sano. Recuperado de http:// www.vivosano.org/es_ES/Informaci\%C3\%B3nparatusalud/Persona/ Alimentaci\%C3\%B3nsana/Gu\%C3\%ADaparacomersano.aspx

Giddens, A. (1997). Sociología. Madrid: Alianza Editorial.

González, A. \& Wallace, S. (1990). Industria cervecera y proceso de alcoholización: el caso de la Cervecería Quilmes. Cuadernos médico sociales, $51,27-43$.

Jiménez-Cruz, B. E. \& Silva-Gutiérrez, C. (2010). Riesgo para trastorno alimentario, ansiedad, depresión y otras emociones asociadas a la exposición de imágenes publicitarias. Anales de psicología, 26(1), 11-17.

Larraín Sundt, M. E., Camus, J., Orellana, Y. \& Arrieta, M. (2009). Estimación de la Validez de Constructo y Consistencia Interna de la Escala de Impacto de las Imágenes Femeninas Presentadas por los Medios sobre Adolescentes Mujeres. Terapia psicológica, 27(1), 27-39.

Ley No 6914 (2012). Programa Derecho Alimentario Saludable. Boletín Oficial de la Secretaria General de la Gobernación de la Provincia del Chaco, 59, 6-8.

López, V. (s.f.). Guerra de las grasas: ¿se puede adelgazar en forma localizada? Clarín. Recuperado de http:/entremujeres.clarin.com/vida-sana/adelgazarbajar_de_peso-grasas-localizadas-panza-cadera-rollitos-grasa-excesoquemar_0_975502524.html

Mancilla Díaz, J. M., Gómez Pérez-Mitré, G., Álvarez, R. G., Franco, P. K., Vázquez, A. R., López, A. X. \& Acosta, G. M. (2006). Trastornos del comportamiento alimentario en México. En J. M. Mancilla Díaz \& G. Gómez Pérez-Mitré (Eds.), Trastornos alimentarios en Hispanoamérica (pp. 89-122). México: El Manual Moderno.

Martín Criado, E. (2007). El conocimiento nutricional apenas altera las prácticas de alimentación: el caso de las madres de clases populares en Andalucía. Revista Española de Salud Pública, 81(5), 519-528.

Martín Criado, E. \& Moreno Pestaña, J. L. (2005). Conflictos sobre lo sano, Un 
estudio sociológico de la alimentación en las clases populares en Andalucía. Sevilla, España: Conserjería de Salud.

Ministerio de Salud (s. f.). Dirección Nacional de Salud Mental y Adicciones. Salud Mental y Adicciones. Recuperado de http://www.msal.gov.ar/ saludmental/index.php/informacion-para-la-comunidad/ique-es-la-saludmental-y-las-adicciones

Nunes, M. A. (2006). Trastornos alimentarios en Brasil: un país de contrastes. En J. M. Mancilla Díaz \& G. Gómez Pérez-Mitré (Eds.), Trastornos alimentarios en Hispanoamérica (pp. 25-42). México: El Manual Moderno.

Núñez Virgen, M. (2012). Trae el cuerpo que Tienes y llévate el que quieres!!! Recuperado de http://www.cirugiaplasticaentijuana.com/cirugia-plastica-3/ cirugiacorporal/lipoescultura/lipoescultura-2/

Organización Mundial de la Salud (2013). 10 datos sobre Obesidad. Recuperado de http://www.who.int/features/factfiles/obesity/es

Orlando, H. (2006, 16 de febrero). Dietas Polémicas: ahora dicen que con comer bien no. Clarín. Recuperado de http://weblog.maimonides.edu/ gerontologia2006/2006/02/dietas_polemicas_ahora_dicen_q.html

Pelaez Fernández, M. A., Labrador Encinas, F. J. \& Raich Escursell, R. M. (2006). Epidemiología de los trastornos del comportamiento alimentario en España. En J. M. Mancilla Díaz \& G. Gómez Pérez-Mitré (Eds.), Trastornos alimentarios en Hispanoamérica (pp. 73-88). México: El Manual Moderno.

Polivy J. \& Herman, C. P. (2002). Causes of Eating Disorders, Annual Review of Psychology, 53, pp. 187-213.

Rutsztein, G. (1997). El aspecto central de la anorexia nerviosa, Revista del Instituto de Investigaciones de la Facultad de Psicología, 2(1), 103-128.

Skatrud-Mickelson, M., Adachi-Mejia, A. M., MacKenzie, T. A. \& Sutherland, L. A. (2012). Giving the wrong impression: food and beverage brand impressions delivered to youth through popular movies. Journal of Public Health, 34(2), 245-252.

Stolkiner, A. (2005, octubre). Interdisciplina y Salud Mental. Trabajo presentado en IX Jornadas Nacionales de Salud Mental. I Jornada Provincial de Psicología. Salud Mental y mundialización: Estrategias posibles en la Argentina de Hoy. Posadas, Misiones, Argentina. 
Strasburger, V. C. (2010). Children, Adolescents, Substance Abuse, and the Media. Pediatrics, 126(4), 791-799.

The World Bank (2014). Word Data Bank. World Development Indicators. Recuperado de http://databank.worldbank.org/data/views/reports/tableview. aspx?isshared $=$ true

Toro, J. (2006). Medios y trastornos del comportamiento alimentario. En J. M. Mancilla Díaz \& G. Gómez Pérez-Mitré (Eds.), Trastornos alimentarios en Hispanoamérica (pp. 203-223). México: El Manual Moderno.

Vivas, E. \& Luigli, Z. (2006). Trastornos del comportamiento alimentario en Venezuela: panorama actual. En J. M. Mancilla Díaz \& G. Gómez PérezMitré (Eds.), Trastornos alimentarios en Hispanoamérica (pp. 173-202). México: El Manual Moderno.

Woodside D. B. \& Garfinkel, P.E. (1989). An overview of the eating disorders anorexia nervosa and bulimia nervosa. Nutrition Today, 24(3), 27-29. 
